\title{
Model for Dredging a Horizontal Trapezoidal Open Channel with Hydraulic Jump
}

\author{
Asuquo E. Eyo \\ Department of Mathematics and Statistics, University of Uyo, Uyo, Nigeria \\ E-mail: asuquoessieneyo@yahoo.com
}

Received: February 7, 2012 Accepted: February 21, 2012 Online Published: May 29, 2012

doi:10.5539/jmr.v4n3p132 URL: http://dx.doi.org/10.5539/jmr.v4n3p132

\begin{abstract}
Mathematical model for dredging a trapezoidal open channel with hydraulic jump is developed using conditions of geometrical and dynamical similarities coupled with continuity and interpolation technique. Parameters like crosssectional area, wetted perimeter, hydraulic mean depth, mean velocity etc. are determined in both the original and new (excavated) channels. A channel flow problem is solved using the model and the results obtained attest to the validity and efficiency of the model. Further application of the model in Bernoulli's equation leads to the energy dissipated in the jump for both the original and new channels. This application enables other parameters like jump efficiency, relative energy loss, power loss and height of the jump to be determined also and compared in both channels.
\end{abstract}

Keywords: Mathematical model, Trapezoidal channel, Hydraulic jump, Dredging

\section{Introduction}

An open channel is a duct through which a liquid flows with a free surface; viz: spillways, canals, rivers, aquaducts, etc. On the other hand, hydraulic jump is formed as a result of an abrupt rise of the water surface in the region of impact between rapid and trianquil flows (Chow, 1959). Flow depths before and after the jump are less than and greater than the critical depth respectively. The zone of impact of the jump is characterized by large-scale turbulence, surface waves and energy dissipation (Chanson, 2004). This type of jump is often referred to as the classical hydraulic jump and has been studied extensively by many researchers, notably Leuthensser and Kartha (1972), Wilson (1977), Gill (1980), Hornung et al. (1995), Chiu and Tung (2002), Moramarco et al. (2004), Lin (2006), etc.

Elsebaie and Shabayek (2010) conducted study of the effect of different shapes of corrugated beds on the characteristics of hydraulic jumps. It was found that, for all shapes of corrugated beds,the tail water depth required to form a jump was appreciably smaller than that for the corresponding jump on smooth beds. Further, the length of the jump on the different corrugated beds was less than half of that on smooth beds. The results of their study confirmed the effectiveness of corugated beds for energy dissipation below hydraulic structures.

France (1981) studied a jet assisted hydraulic jump in an open channel. He investigated the stability of the hydraulic jump and the effectiveness of jets over a wide range of operating conditions. He observed that the stabilization of the jump is dependent on a number of parameters but concluded however that the angle of inclinaion of the jets has the most pronounced effect.

Nasser et al. (1980) presented a theoretical and experimental analysis of flow in a channel with a bed slot spanning the entire width of the channel. A simple theoretical expression for the coefficient of discharge for the bed slot was derived and substantiated by experiment. Resolving the momentum equation along the flow direction they obtained a simple equation for the brinks depths ratio which was verified experimentally. Finally, the influence of the slot length on the diverted discharge was evaluated and an empirical formula describing the relationship was proposed.

Nikmehr and Tabebordbar (2010) carried out research in jump study on four adverse slopes, $-0.00125,-0.0025$, -0.00375 and -0.005 in two cases of rough and smooth beds. Their results showed that the sequent depth ratio and the length of the jump were greater on smooth beds than rough beds for the same slopes and Froude number. Also coparison of the percentage of energy loss revealed that more energy loss occurred on rough beds than smooth beds. 
Sholichin and Akib (2010) conducted research in the hydraulics laboratory aimed at obtaining suitability of drop number (D) and an estimated hydraulic jump using the drop number. Their main objective was to obtain the affectivities of application of D on vertical drop and sloped drop structures and to develop the model equation for the sloped drop structure. Their results showed that the D equation could predict drop length $\left(L_{d}\right)$, and hydraulic jump length $\left(L_{j}\right)$ for vertical drop structures but could not estimate the hydaulic jump length for sloped drop structure. Hence, they developed a D equation for sloped drop structures. These equations were shown to have correlation regression with a range between $60-87 \%$ and relative error with a range between $5-13 \%$.

Vatankhah and Omid (2010) discussed direct solution to problems of hydraulic jump in horizontal triangular channels. Noting that no direct solutions were available in technical literature for sequent depth raios in horizontal triangular channels because it was presumed that the governing equation was a quintic equation, they considered this quintic equation and reduced it to a quartic equation. In the next step of their work, the quartic equation was converted to a resolvent cubic equation and two quadratic equations. Their research which showed these steps clearly led to an acceptable physical analytic solution for sequent depth ratios in horizontal triangular channels.

Chanson (2011) investigated experimentally the bubbly two phase flow properties of steady and strong hydraulic jumps. Their results demonstrated that the strong air entrainment rate and the depth-averaged void-fraction data highlighted a rapid deaeration of the jump roller. The results suggested that the hydraulic jumps were effective aerators and that the rate of detrainment was comparatively smaller at the largest Froude numbers.

The motivation of the work is based on the many advantages of hydraulic jump, some of which include: water distribution and mixing of chemicals used for water purification or waste water treatment, dissipation of energy in a moving fluid,thereby preventing the fluid from scouring the channel banks and also as effective aerators.

The soul objective of the work is in the dredging of open channel to increase the discharge in the excavated channel to enhance nagivation. That is, the high-water level in the new channel removes the danger of a ship grounding if it sails too fast. Thus, in this work we consider the dredging of a trapezoidal channel because of its capactity or discharge. Using similarity conditions and interpolation, we determine certain parameters in the original and new channels. By comparing them,we observe that some of the parameters exhibit interesting characteristics.

\section{Mathematical Model for Dredging a Trapezoidal Channel Section}

Throughout,we shall denote the original channel (i. e. the channel before dredging) with the symbol O, while the new channel (i.e. the channel after dredging) shall be denoted by the symbol $\mathrm{N}$. We shall also use the subscripts 1 and 2 to denote the upstream and downstream conditions of the channel respectively.

\subsection{Mathematical Model for the Original Trapezoidal Channel Section}

\subsubsection{Upstream Parameters of the Original Channel}

(i) Cross-sectional area $\left(A_{1}\right)_{0}$.

$$
\left(A_{1}\right)_{0}=\left(h_{1}\right)\left[b+\eta\left(h_{1}\right)_{0}\right]
$$

where $\left(h_{1}\right)_{0}$ is the upstream depth of the channel, $\mathrm{b}$ is the bottom width of the channel and $\eta$ the side slope $=$ horizontal to vertical.

(ii) Wetted perimeter $\left(W_{1}\right)_{0}$.

$$
\left(W_{1}\right)_{0}=b+2\left(h_{1}\right)_{0}\left[1+\eta^{2}\right]^{\frac{1}{2}}
$$

(iii) Hydraulic mean depth $\left(R_{1}\right)_{0}$.

$$
\left(R_{1}\right)_{0}=\frac{\left(A_{1}\right)_{0}}{\left(W_{1}\right)_{0}}
$$

(iv) Mean velocity $\left(u_{1}\right)_{0}$.

$$
\left(u_{1}\right)_{0}=\frac{Q_{0}}{\left(A_{1}\right)_{0}}
$$

where $Q_{0}$ is the discharge in the upstream section of the channel.

(v) Discharge $Q_{0}$

From (4),

$$
Q_{0}=\left(A_{1}\right)_{0}\left(u_{1}\right)_{0} \text {. }
$$

(vi) Froude number $\left(F_{1}\right)_{0}$. 
It is noted that the jump is characterized by the upstream Froude number $F_{1}$, where

$$
F_{1}=\frac{u_{1}}{\sqrt{g h_{1}}}
$$

Thus, by our modelling notation

$$
\left(F_{1}\right)_{0}=\frac{\left(u_{1}\right)_{0}}{\sqrt{g\left(h_{1}\right)_{0}}}
$$

where $g$ is the acceleration due to gravity.

\subsubsection{Downstream Parameters of the Original Channel}

(vii) Downstream depth $\left(h_{2}\right)_{0}$.

Here, the model for $\left(h_{2}\right)_{0}$ is developed below and its value is determined from Table 1 (Table 1 is taken from the "Handbook of Hydraulics" by King and Barter, 1996).

Model for $\left(h_{2}\right)_{0}$.

Let

$$
\left(x_{1}\right)_{0}=\frac{\left(h_{1}\right)_{0}}{\left(E_{1}\right)_{0}}=\alpha \text {, }
$$

and

$$
\left(y_{1}\right)_{0}=\frac{\eta\left(E_{1}\right)_{0}}{b}=\beta
$$

where

$$
\left(E_{1}\right)_{0}=\left[\frac{\left(u_{1}\right)_{0}^{2}}{2 g}+\left(h_{1}\right)_{0}\right]
$$

is the specific energy upstream the original channel.

By entering Table 1 with the values $\frac{\left(h_{1}\right)_{0}}{\left(E_{1}\right)_{0}}=\alpha$ and $\frac{\eta\left(E_{1}\right)_{0}}{b}=\beta$ and interpolating,the value $\left(x_{2}\right)_{0}$ can be read. Let $\left(x_{2}\right)_{0}=\gamma$, say.

Then the downstream depth $\left(h_{2}\right)_{0}$ is given by King and Barter (1996).

$$
\left(h_{2}\right)_{0}=\left(x_{2}\right)_{0}\left(E_{1}\right)_{0}=\gamma\left[\frac{\left(u_{1}\right)_{0}}{2 g}+\left(h_{1}\right)_{0}\right]
$$

(viii) Cross-sectional area $\left(A_{2}\right)_{0}$.

$$
\left(A_{2}\right)_{0}=\left(h_{2}\right)_{0}\left[b+\eta\left(h_{2}\right)_{0}\right]
$$

(ix) Wetted perimeter $\left(W_{2}\right)_{0}$.

$$
\left(W_{2}\right)_{0}=b+2\left(h_{2}\right)_{0}\left[1+\eta^{2}\right]^{\frac{1}{2}}
$$

(x) Hydraulic mean depth $\left(R_{2}\right)_{0}$.

$$
\left(R_{2}\right)_{0}=\frac{\left(A_{2}\right)_{0}}{\left.W_{2}\right)_{0}}
$$

(ix) Mean velocity $\left(u_{2}\right)_{0}$.

From continuity (Chow, 1959)

$$
\left.\left.\left(A_{1}\right)_{0}\left(u_{1}\right)_{0}=\left(A_{2}\right)_{0}\right) u_{2}\right)_{0}=Q_{0}
$$

so that

$$
\left(u_{2}\right)_{0}=\frac{Q_{0}}{\left(A_{2}\right)_{0}}
$$

(x) Discharge $Q_{0}$.

From (16)

$$
Q_{0}=\left(A_{2}\right)_{0}\left(u_{2}\right)_{0}
$$


(xi) Froude number $\left(F_{2}\right)_{0}$.

$$
\left(F_{2}\right)_{0}=\frac{\left(u_{2}\right)_{0}}{\sqrt{g\left(h_{2}\right)_{0}}}
$$

\subsection{Model for the New Trapezoidal Section}

2.2.1 Upstream Parameters for the New Channel

(xii) Cross-sectional area $\left(A_{1}\right)_{N}$.

$$
\left(A_{1}\right)_{N}=\left(h_{1}\right)_{N}\left[b+\eta\left(\left(h_{1}\right)_{N}\right]\right.
$$

where $\left(h_{1}\right)_{N}$ is the upstream depth of the new channel (xiii) Wetted perimeter $\left(W_{1}\right)_{N}$.

$$
\left(W_{1}\right)_{N}=b+2\left(h_{1}\right)_{N}\left[1+\eta^{2}\right]^{\frac{1}{2}}
$$

(xiv) Hydraulic mean depth $\left(R_{1}\right)_{N}$.

$$
\left(R_{1}\right)_{N}=\frac{\left(A_{1}\right)_{N}}{\left(W_{1}\right)_{N}}
$$

(xv) Mean velocity $\left(u_{1}\right)_{N}$.

For dynamical similarity, the Froude numbers will be identical at all corresponding points in the original and new channels. Thus, for the upstream section of the two channels,

$$
\frac{\left(u_{1}\right)_{0}^{2}}{g\left(h_{1}\right)_{0}}=\frac{\left(u_{1}\right)_{N}^{2}}{g\left(h_{1}\right)_{N}}
$$

So that

$$
\left(u_{1}\right)_{N}=\left[\frac{\left(u_{1}\right)_{0}^{2} \cdot g\left(h_{1}\right)_{N}}{g\left(h_{1}\right)_{0}}\right]^{\frac{1}{2}}
$$

(xvi) Discharge $Q_{N}$.

Again, by continuity (Chow, 1959)

$$
Q_{N}=\left(A_{1}\right)\left(u_{1}\right)_{N}=\left(A_{1}\right)_{N}\left[\frac{\left(u_{1}\right)_{0}^{2} \cdot g\left(h_{1}\right)_{N}}{g\left(h_{1}\right)_{0}}\right]
$$

(using (23))

(xvii) Froude number $\left(F_{1}\right)_{N}$.

$$
\left(F_{1}\right)_{N}=\frac{\left(u_{1}\right)_{N}}{\sqrt{g\left(h_{1}\right)_{N}}}
$$

2.2.2 Downstream Parameters for the New Channel

(xviii) Downstream depth $\left(h_{2}\right)_{N}$.

From geometrical similarity for the original and new channels

$$
\frac{\left(h_{1}\right)_{0}}{\left(h_{2}\right)_{0}}=\frac{\left(h_{1}\right)_{N}}{\left(h_{2}\right)_{N}}
$$

so that

$$
\left(h_{2}\right)_{N}=\frac{\left(h_{2}\right)_{0} \cdot\left(h_{1}\right)_{N}}{\left(h_{1}\right)_{0}}
$$

(xix) Cross-sectional area $\left(A_{2}\right)_{N}$.

$$
\left(A_{2}\right)_{N}=\left(h_{2}\right)_{N}\left[b+\eta\left(h_{2}\right)_{N}\right]
$$

(xx) Wetted perimeter $\left(W_{2}\right)_{N}$.

$$
\left(W_{2}\right)_{N}=b+2\left(h_{2}\right)_{N}\left[1+\eta^{2}\right]^{\frac{1}{2}}
$$

(xxi) Hydraulic mean depth $\left(R_{2}\right)_{N}$.

$$
\left(R_{2}\right)_{N}=\frac{\left(A_{2}\right)_{N}}{\left.W_{2}\right)_{N}}
$$


(xxii) Mean velocity $\left(u_{2}\right)_{N}$.

Again, from dynamical similarity

$$
\frac{\left(u_{2}\right)_{0}^{2}}{g\left(h_{2}\right)_{0}}=\frac{\left(u_{2}\right)_{N}^{2}}{g\left(h_{2}\right)_{N}}
$$

so that

$$
\left(u_{2}\right)_{N}=\left[\frac{\left(u_{2}\right)_{0}^{2} \cdot g\left(h_{2}\right)_{N}}{g\left(h_{2}\right)_{0}}\right]
$$

(xxiii) Discharge $Q_{N}$.

From Chow (1959)

$$
Q_{N}=\left(A_{1}\right)_{N}\left(u_{1}\right)_{N}=\left(A_{2}\right)_{N}\left(u_{2}\right)_{N}=\left(A_{2}\right)_{N}\left[\frac{\left(u_{2}\right)_{0}^{2} \cdot g\left(h_{2}\right)_{N}}{g\left(h_{2}\right)_{0}}\right]
$$

(using (32))

(xxiv) Froude number $\left(F_{2}\right)_{N}$.

$$
\left(F_{2}\right)_{N}=\frac{\left(u_{2}\right)_{N}}{\sqrt{g\left(h_{2}\right)_{N}}}
$$

2.3 Model for Energy Loss, Jump Efficiency, Relative Energy Loss, Power Loss and Height of the Jump

The energy loss $h_{f}$ occuring between the two sections of the channel as determined from Bernoulli's equation for any streamline between points 1 and 2 of the hydraulic jump is

$$
h_{f}=\left[\frac{u_{1}^{2}}{2 g}+h_{1}\right]-\left[\frac{u_{1}^{2}}{2 g}+h_{2}\right]
$$

or

$$
h_{f}=E_{1}-E_{2}
$$

where

$$
E_{1}=\frac{u_{1}^{2}}{2 g}+h_{1}
$$

and

$$
E_{2}=\frac{u_{2}^{2}}{2 g}+h_{2}
$$

Here $E_{1}$ and $E_{2}$ denote the specific energies (or energy heads) before and after the jump respectively. It is elementary to see that (35) yields after simplification

$$
h_{f}=\frac{\left(h_{2}-h_{1}\right)^{3}}{4 h_{1} h_{2}}
$$

Applying our modeling notatin, we obtain from (39).

(xxv) Energy loss in the original channel $\left(h_{f}\right)_{0}$.

$$
\left(h_{f}\right)_{0}=\frac{\left[\left(h_{2}\right)_{0}-\left(h_{1}\right)_{0}\right]^{3}}{4\left(h_{1}\right)_{0}\left(h_{2}\right)_{0}}
$$

(xxvi) Energy loss in the new channel $\left(h_{f}\right)_{N}$.

$$
\left(h_{f}\right)_{N}=\frac{\left[\left(h_{2}\right)_{N}-\left(h_{1}\right)_{N}\right]^{3}}{4\left(h_{1}\right)_{N}\left(h_{2}\right)_{N}}
$$

From (37) and (38) we have

(xxvii) Jump efficiency for the original channel:

$$
\frac{\left(E_{2}\right)_{0}}{\left(E_{1}\right)_{0}}=\frac{\frac{\left(u_{2}\right)_{0}^{2}}{2 g}+\left(h_{2}\right)_{0}}{\frac{\left(u_{1}\right)_{0}^{2}}{2 g}+\left(h_{1}\right)_{0}}
$$


(xxviii) Jump efficiency for the new channel:

$$
\frac{\left(E_{2}\right)_{N}}{\left(E_{1}\right)_{N}}=\frac{\frac{\left(u_{2}\right)_{N}^{2}}{2 g}+\left(h_{2}\right)_{N}}{\frac{\left(u_{1}\right)_{N}^{2}}{2 g}+\left(h_{1}\right)_{N}}
$$

(xxix) Relative energy loss for the original channel:

$$
\frac{\left(E_{1}\right)_{0}-\left(E_{2}\right)_{0}}{\left(E_{1}\right)_{0}}=1-\frac{\left(E_{2}\right)_{0}}{\left(E_{1}\right)_{0}}
$$

(xxx) Relative energy loss for the new channel:

$$
\frac{\left(E_{1}\right)_{N}-\left(E_{2}\right)_{N}}{\left(E_{1}\right)_{N}}=1-\frac{\left(E_{2}\right)_{N}}{\left(E_{1}\right)_{N}}
$$

\subsubsection{Power Loss in the Jump}

Let $P$ denote the power loss in the jump. Then by our modeling notation, we find

(xxxi) Power loss for the original channel $P_{0}$.

$$
P_{0}=\rho g Q_{0}\left(h_{f}\right)_{0}
$$

where $\rho$ is the fluid density.

(xxxii) Power loss for the new channel $P_{N}$.

$$
P_{N}=\rho g Q_{N}\left(h_{f}\right)_{N}
$$

2.3.2 Height of the Jump

Finally, let $H$ denote the height of the jump. Then by our notation, we have

(xxxiii) Height of the jump in the original channel $H_{0}$.

$$
H_{0}=\left(h_{2}\right)_{0}-\left(h_{1}\right)_{0}
$$

(xxxiv) Height of the jump in the new channel $H_{N}$.

$$
H_{N}=\left(h_{2}\right)_{N}-\left(h_{1}\right)_{N}
$$

\section{Numerical Illustration}

Consider, for instance, a trapezoidal channel with hydraulic jump haveing 3:2 side slopes $(\eta)$. The channel conveys waer at the rate of $250 \mathrm{~m}^{3} / \mathrm{s}$ and the depth of water before the jump occurs is $1.5 \mathrm{~m}$. Using the model we wish to determine, after dredging the channel (a) the new discharge, (b) the new cross-section area, (c) the new downstream depth, (d) the new energy dissipated in the jump (i.e. energy loss), (e) the new relative energy loss, (f) the new jump efficiency, $(\mathrm{g})$ the new power loss and $(\mathrm{h})$ the new height of the jump if the excavation must be to the depth of $2.5 \mathrm{~m}$ upstream.

\section{Solution}

\subsection{Original Channel}

\subsubsection{Upstream Data}

From the problem, $\left(h_{1}\right)_{0}=1.5 \mathrm{~m}, \quad b=20 \mathrm{~m}, \quad \eta=\frac{3}{2}=1.5, Q_{0}=250 \mathrm{~m}^{3} / \mathrm{s}$.

Substituting these data appropriately in the expressions (1) - (4) and (7), we obtain respectively

$$
\begin{gathered}
\left(A_{1}\right)_{0}=33.375 \mathrm{~m}^{2}, \quad\left(W_{1}\right)_{0}=25.408 \mathrm{~m}, \quad\left(R_{1}\right)_{0}=1.3135 \mathrm{~m} \\
\left(u_{1}\right)_{0}=7.490 \mathrm{~m} / \mathrm{s}, \quad\left(F_{1}\right)_{0}=1.9527
\end{gathered}
$$




\subsubsection{Downstream Data}

Using the above data in (8) and (9) we find respectively $\alpha=0.34$ and $\beta=0.32$. Entering Table 1 with the values $\frac{\left(h_{1}\right)_{0}}{\left(E_{1}\right)_{0}}=0.34=\alpha$ and $\frac{\eta\left(E_{1}\right)_{0}}{b}=0.32=\beta$ and interpolating, we obtain the value $\left(x_{2}\right)_{0}=\gamma=0.78$. Thus, the downstream depth $\left(h_{2}\right)_{0}$ for the original channel becomes (King \& Barter, 1996)

$$
\left(h_{2}\right)_{0}=\left(x_{2}\right)_{0}\left(E_{1}\right)_{0}=(0.78)(4.35979)=3.3570 m
$$

since

$$
\left(E_{1}\right)_{0}=\frac{\left(u_{1}\right)_{0}^{2}}{2 g}+\left(h_{1}\right)_{0}=4.35979
$$

Applying the value of $\left(h_{2}\right)_{0}$ with $b=20 m, \eta=\frac{3}{2}$ in the model (12) - (14) and (16) - (18) we have respectively

$$
\begin{gathered}
\left(A_{2}\right)_{0}=84.044 m^{2}, \quad\left(W_{2}\right)_{0}=32.103 m, \\
\left(R_{2}\right)_{0}=2.6178 m, \quad\left(u_{2}\right)_{0}=2.974 m / s \\
Q_{0}=250 m^{3} / s, \quad\left(F_{2}\right)_{0}=0.51834
\end{gathered}
$$

\subsection{New Channel}

\subsubsection{Upstream Data}

Here $\left(h_{1}\right)_{N}=2.5 m, \quad b=20 m, \quad \eta=\frac{3}{2}$. Substituting these data appropriately in the relations (19)- (21) and (23) (25) we obtain respectively

$$
\begin{gathered}
\left(A_{1}\right)_{N}=59.375 m^{2}, \quad\left(W_{1}\right)_{N}=29.013 m \\
\left(R_{1}\right)_{N}=2.0464 m, \quad\left(u_{1}\right)_{N}=9.670 m / s \\
Q_{N}=574.174 m^{3} / s, \quad\left(F_{1}\right)_{N}=1.9526
\end{gathered}
$$

\subsubsection{Downstream Data}

The parameters $\left(h_{2}\right)_{N},\left(A_{2}\right)_{N},\left(W_{2}\right)_{N},\left(R_{2}\right)_{N},\left(u_{2}\right)_{N}, Q_{N}$ and $\left(F_{2}\right)_{N}$ for the new channel are determined respectively via appropriate substitution of the data above in (27) - (30) and (32) - (34). The result is

$$
\begin{gathered}
\left(h_{2}\right)_{N}=5.595 m, \quad\left(A_{2}\right)_{N}=158.856 m^{2} \\
\left(W_{2}\right)_{N}=40.173 m, \quad\left(R_{2}\right)_{N}=3.9542 m \\
\left(u_{2}\right)_{N}=3.840 m / s, \quad Q_{N}=574.174 m^{3} / \mathrm{s} \\
\left(F_{2}\right)_{N}=0.51834 .
\end{gathered}
$$

Finally, the energy loss, jump efficiency, relative energy loss, power loss and height of the jump for the original channel are determined respectively through appropriate substitution of the above data in the expressions (40), (42), (44), (46), (48).

Thus, we obtain:

$$
\begin{gathered}
\left(h_{f}\right)_{0}=0.31793 m, \frac{\left(E_{2}\right)_{0}}{\left(E_{1}\right)_{0}}=87.34 \% \\
1-\frac{\left(E_{2}\right)_{0}}{\left(E_{1}\right)_{0}}=0.12656, \quad P_{0}=779.726 K \mathrm{~W} \\
H_{0}=1.857 \mathrm{~m} .
\end{gathered}
$$

Similarly, substituting the above data appropriately in the model (41), (43), (45), (47), (49) yields respectively the energy loss, jump efficiency, relative energy loss, power loss and height of the jump for the new channel.

The result is:

$$
\begin{gathered}
\left(h_{f}\right)_{N}=0.52988 m, \frac{\left(E_{2}\right)_{N}}{\left(E_{1}\right)_{N}}=87.34 \% \\
1-\frac{\left(E_{2}\right)_{N}}{\left(E_{1}\right)_{N}}=0.12656, \quad P_{N}=2984.657 \mathrm{KW}
\end{gathered}
$$




$$
H_{N}=3.095 m \text {. }
$$

\section{Results}

The results for the original channel are shown in Table 2 while those for the new channel are shown in Table 3.

\section{Discussion}

Table 1 shows the depth after the jump (King \& Barter, 1996). Tables 2 and 3 display the values of the parameters of the original and new (excavated) channels respectively. The study of Tables 2 and 3 reveals that the downstream parameters, namely, the downstream depth, area of cross-section, wetted perimeter and hydraulic mean depth are generally greater in both the original and new channels than the upstream ones. This is in agreement with model expressions (11) - (14) and (27) - (30) of the original and new channels respectively. On the other hand, these same parameters upstream and downstream are greater in the new channel than their counterparts in the original channel. This is also in agreement with the model (1) - (3) (upstream), (11) - (14) (downstream) of the original channel and (19) - (21) (upstream), (27) - (30) (downstream) of the new channel. However, this trend is reversed in the case of the Froude number which is lower in the downstream section of both channels than in the upstream section; but, strikingly, the upstream Froude number is the same as the downstream Froude number in each channel. This agrees with the model (7) and (18) for the original channel and (25) and (34) for the new channel. It is also observed from Tables 2 and 3 that the upstream and downstream velocities in the new channel are respectively greater than the upstream and downstream ones in the original channel. Another feature is that whereas the discharge, energy loss, power loss and height of the jump are greater in the new channel than the original one, the jump efficiency and relative energy loss, on the other hand, remain unchanged in both channels.

\section{Conclusion}

From Tables 2 and 3, it becomes very clear that the discharge and the jump in the new channel are greater than their counterparts in the original one. Hence, the new channel greatly enhances navigation while its jump dissipates greater energy for mixing of chemicals used for water purification or waste water treatment.

\section{References}

Chanson, H. (2004). The Hydraulics of Open Channel Flows: An Introduction (2nd ed.). Oxford: ButterworthHeinemann.

Chanson, H. (2011). Bubbly Two-Phase Flow in Hydraulic Jumps at Large Froude Numbers. Journal of Hydraulic Engineeriing, 137, 451. http://dx.doi.org/10.1061/(ASCE)HY.1943-7900.0000323

Chiu, C. L., \& Tung, N. C. (2002). Maximum Velocity and Regularities in Open Channel Flow. Journal of Hydraulic Engineering, 128, 390-398. http://dx.doi.org/10.1061/(ASCE)0733-9429(2002)128:4(390)

Chow, V. T. (1959). Open Channel Hydraulics. New York: McGraw-Hill.

Elsebaie, I. H., \& Shabayek, S. (2010). Formation of Hydraulic Jumps on Corugated Beds. International Journal of Civil and Environmental Engineering IJCEE-IJENS, 10(1), 40-54.

France, P. W. (1981). An Investigation of a Jet-Assisted Hydraulic Jump. Journal of Hydraulic Research, 19(4), 325-337. http://dx.doi.org/10.1080/00221688109499507

Gill, M. A. (1980). Hydraulics of Rectangular Vertical Drop Structures. Journal of Hydraulic Research, 28(4), 355-369.

Horung, H. G., Willert, C. E., \& Turner, S. (1995). The Flow Field Downstream of a Hydraulic Jump. Journal of Fluid Mechanics, 287, 299-316. http://dx.doi.org/10.1017/S0022112095000966

King, H. W., \& Barter, E. F. (1996). Handbook of Hydralics (7th ed.). New York: McGraw-Hill. ISBN 10:0070072477.

Leuthensser, H. J., \& Kartha, V. C. (1972). Effect of Inflow Condition on Hydraulic Jump. Journal of Hydraulic Division, 98, HY 18, 1367-1385.

Lin, D. A. (2006). Regression Residuals and Mean Profile in Uniform Open Channel Flow. Journal of Hydrology engineering, 126, 24-32.

Moramarco, T., \& Singh, V. P. (2004). Estimation of Mean Velocity in Natural Channels Based on Chiu's Velocity Districution Equation. Journal of Hydrology Engineering, $9, \quad 42-50$. 
http://dx.doi.org/10.1061/(ASCE)1084-0699(2004)9:1(42)

Nasser, M. S., Venkataraman, P., \& Ramamurthy, A. S. (1980). Flow in a Channel with a Slot in the Bed. Journal of Hydraulic Research, 18(4), 359-367. http://dx.doi.org/10.1080/00221688009499541

Nikmehr, S., \& Tabebordbar, A. (2010). Hydraulic Jumps on Adverse Slope in Two Cases of Rough and Smooth Bed. Research Journal of Applied Sciences, Engineering and Technology, 2(1), 19-22.

Sholichin, M., \& Akib, S. (2010). Development of Drop Number Peformance for Estimate Hydraulic Jump on Vertical and Sloped Drop Structure. International Journal of the Physical Sciences, 5(11), 1678-1687.

Vatankhah, A. R., \& Omid, M. H. (2010). Direct Solution to Problems of Hydraulic Jump in Horizontal Triangular Channels. Applied Mathematics Letters, 23(9), 1104-1108. http://dx.doi.org/10.1016/j.aml.2010.04.044

Table 1. Depth after hydraulic jump for trapezoidal channels (King \& Barter - 1996)

\begin{tabular}{|c|c|c|c|c|c|c|c|c|c|c|c|c|c|}
\hline$\left(x_{1}\right)_{0}=\frac{\left(h_{1}\right)_{0}}{\left(E_{1}\right)_{0}}$ & & & & & & & $\left(y_{1}\right)_{0}=\frac{\eta\left(E_{1}\right)_{0}}{b}$ & & & & & & \\
\hline & 0 & 0.1 & 0.2 & 0.3 & 0.4 & 0.5 & 0.6 & 0.7 & 0.8 & 0.9 & 1.0 & 10 & $\infty$ \\
\hline \multirow[t]{2}{*}{.05} & .99 & .99 & & & & & & & & & & & \\
\hline & .41 & .41 & .40 & .39 & .39 & .38 & .38 & .37 & .37 & .36 & .36 & .31 & .24 \\
\hline \multirow[t]{2}{*}{.10} & .99 & .99 & .99 & .99 & .99 & & & & & & & & \\
\hline & .56 & .55 & .55 & .54 & .53 & .53 & .52 & .52 & .51 & .51 & .50 & .42 & .37 \\
\hline \multirow[t]{2}{*}{.15} & .98 & .98 & .99 & .99 & .99 & .99 & .99 & .99 & .99 & .99 & .99 & & \\
\hline & .65 & .64 & .64 & .63 & .62 & .62 & .61 & .61 & .61 & .60 & .60 & .52 & .48 \\
\hline \multirow[t]{2}{*}{.20} & .97 & .97 & .98 & .98 & .98 & .98 & .99 & .99 & .99 & .98 & .99 & & \\
\hline & .71 & .70 & .70 & .69 & .69 & .69 & .68 & .68 & .68 & .67 & .67 & .60 & .56 \\
\hline \multirow[t]{2}{*}{.25} & .95 & .95 & .96 & .97 & .97 & .97 & .98 & .98 & .98 & .98 & .98 & .99 & \\
\hline & .75 & .75 & .74 & .74 & .74 & .73 & ..73 & .73 & .73 & .73 & .72 & .66 & .63 \\
\hline \multirow[t]{2}{*}{.30} & .92 & .93 & .94 & .95 & .95 & .96 & .97 & .97 & .97 & .97 & .97 & .99 & \\
\hline & .78 & .78 & .78 & .78 & .77 & .77 & .77 & .77 & .77 & .77 & .77 & .72 & .69 \\
\hline \multirow[t]{2}{*}{.35} & .90 & .91 & .92 & .93 & .94 & .94 & .95 & .95 & .95 & .95 & .96 & .98 & .99 \\
\hline & .79 & .80 & .80 & .80 & .80 & .80 & .80 & .80 & .80 & .80 & .80 & .76 & .76 \\
\hline \multirow[t]{2}{*}{.40} & .87 & .89 & .90 & .91 & .92 & .92 & .93 & .93 & .94 & .94 & .95 & .98 & .99 \\
\hline & .80 & .80 & .81 & .81 & .81 & .82 & .82 & .82 & .82 & .82 & .82 & .80 & .79 \\
\hline \multirow[t]{2}{*}{.45} & .84 & .86 & .87 & .88 & .89 & .90 & .91 & .91 & .92 & .92 & .93 & .97 & .98 \\
\hline & .80 & .80 & .81 & .82 & .82 & .83 & .83 & .83 & .83 & .83 & .83 & .83 & .83 \\
\hline \multirow[t]{2}{*}{.50} & .81 & .83 & .85 & .86 & .87 & .87 & .88 & .89 & .90 & .90 & .91 & .96 & .97 \\
\hline & .78 & .79 & .80 & .80 & .81 & .82 & .83 & .83 & .83 & .84 & .84 & .86 & .85 \\
\hline \multirow[t]{2}{*}{.55} & .77 & .79 & .81 & .82 & .83 & .85 & .86 & .87 & .87 & .88 & .88 & .94 & .95 \\
\hline & .76 & .77 & .78 & .79 & .80 & .81 & .82 & .83 & .83 & .83 & .84 & .87 & .87 \\
\hline \multirow[t]{2}{*}{.60} & .73 & .77 & .79 & .80 & .82 & .82 & .83 & .84 & .85 & .85 & .92 & .93 & \\
\hline & .73 & .74 & .76 & .77 & .79 & .80 & .81 & .81 & .82 & .82 & .83 & .87 & .88 \\
\hline \multirow[t]{2}{*}{.65} & .69 & .71 & .73 & .74 & .76 & .78 & .79 & .80 & .81 & .81 & .82 & .89 & .91 \\
\hline & .69 & .71 & .73 & .74 & .76 & .77 & .78 & .79 & .80 & .80 & .81 & .87 & .88 \\
\hline \multirow[t]{2}{*}{.70} & $\ldots$ & $\ldots$ & $\ldots$ & $\ldots$ & .72 & .73 & .74 & .75 & .76 & .77 & .78 & .86 & .88 \\
\hline & $\ldots$ & $\ldots$ & $\ldots$ & $\ldots$ & .72 & .73 & .74 & .75 & .76 & .77 & .78 & .85 & .87 \\
\hline \multirow[t]{2}{*}{.75} & $\ldots$ & $\ldots$ & $\ldots$ & $\ldots$ & $\ldots$ & $\ldots$ & $\ldots$ & $\ldots$ & $\ldots$ & $\ldots$ & $\ldots$ & .83 & .85 \\
\hline & 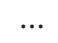 & $\ldots$ & $\cdots$ & $\ldots$ & $\cdots$ & $\cdots$ & $\cdots$ & & & & & .83 & .84 \\
\hline D. & .67 & .68 & .69 & .70 & .71 & .72 & .72 & .73 & .73 & .74 & .74 & .79 & .80 \\
\hline
\end{tabular}


Table 2. Result for the original channel

Original Channel with Jump

\begin{tabular}{|c|c|c|}
\hline Characteristics & Upstream Parameters & Downstream Parameters \\
\hline Side slope & $\frac{3}{2}$ & $\frac{3}{2}$ \\
\hline Depth & $1.50 \mathrm{~m}$ & $3.357 \mathrm{~m}$ \\
\hline Width & $20 \mathrm{~m}$ & $20 \mathrm{~m}$ \\
\hline Area of cross-section & $33.375 m^{2}$ & $84.044 m^{2}$ \\
\hline Wetted perimeter & $25.408 \mathrm{~m}$ & $32.103 \mathrm{~m}$ \\
\hline Hydraulic mean depth & $1.313 \mathrm{~m}$ & $2.618 \mathrm{~m}$ \\
\hline Mean velocity & $7.490 / \mathrm{s}$ & $2.974 \mathrm{~m} / \mathrm{s}$ \\
\hline Discharge & $250 \mathrm{~m}^{3} / \mathrm{s}$ & $250 \mathrm{~m}^{3} / \mathrm{s}$ \\
\hline Froude number & 1.9527 & 0.5183 \\
\hline Energy loss & \multicolumn{2}{|c|}{$0.31793 \mathrm{~m}$} \\
\hline Jump efficiency & \multicolumn{2}{|c|}{$87.34 \%$} \\
\hline Relative energy loss & \multicolumn{2}{|c|}{0.12656} \\
\hline Power loss & \multicolumn{2}{|c|}{$779.726 \mathrm{KW}$} \\
\hline Height of the jump & \multicolumn{2}{|c|}{$1.857 \mathrm{~m}$} \\
\hline
\end{tabular}

Table 3. Result for the new channel

New (Excavated) channel with jump

\begin{tabular}{|c|c|c|}
\hline Characteristics & Upstream Parameters & Downstream Parameters \\
\hline Side slope & $\frac{3}{2}$ & $\frac{3}{2}$ \\
\hline Depth & $2.50 \mathrm{~m}$ & $5.595 \mathrm{~m}$ \\
\hline Width & $20 \mathrm{~m}$ & $20 \mathrm{~m}$ \\
\hline Area of cross-section & $59.375 m^{2}$ & $158.856 m^{2}$ \\
\hline Wetted perimeter & $29.013 \mathrm{~m}$ & $40.173 \mathrm{~m}$ \\
\hline Hydraulic mean depth & $2.046 \mathrm{~m}$ & $3.954 \mathrm{~m}$ \\
\hline Mean velocity & $9.670 \mathrm{~m} / \mathrm{s}$ & $3.840 \mathrm{~m} / \mathrm{s}$ \\
\hline Discharge & $574.174 \mathrm{~m}^{3} / \mathrm{s}$ & $574.174 \mathrm{~m}^{3} / \mathrm{s}$ \\
\hline Froude number & 1.9527 & 0.5183 \\
\hline Energy loss & \multicolumn{2}{|c|}{$0.52988 \mathrm{~m}$} \\
\hline Jump efficiency & \multicolumn{2}{|c|}{$87.34 \%$} \\
\hline Relative energy loss & \multicolumn{2}{|c|}{0.12656} \\
\hline Power loss & \multicolumn{2}{|c|}{$2984.657 \mathrm{KW}$} \\
\hline Height of the jump & \multicolumn{2}{|c|}{$3.095 \mathrm{~m}$} \\
\hline
\end{tabular}

